\title{
Complex Calculations: How Drug Use During Pregnancy Becomes a Barrier to Prenatal Care
}

\author{
Sarah C. M. Roberts • Cheri Pies
}

Published online: 16 March 2010

(c) The Author(s) 2010. This article is published with open access at Springerlink.com

\begin{abstract}
Pregnant women who use drugs are more likely to receive little or no prenatal care. This study sought to understand how drug use and factors associated with drug use influence women's prenatal care use. A total of 20 semi-structured interviews and 2 focus groups were conducted with a racially/ethnically diverse sample of lowincome women using alcohol and drugs in a California county. Women using drugs attend and avoid prenatal care for reasons not connected to their drug use: concern for the health of their baby, social support, and extrinsic barriers such as health insurance and transportation. Drug use itself is a barrier for a few women. In addition to drug use, women experience multiple simultaneous risk factors. Both the drug use and the multiple simultaneous risk factors make resolving extrinsic barriers more difficult. Women also fear the effects of drug use on their baby's health and fear being reported to Child Protective Services, each of which influence women's prenatal care use. Increasing the number of pregnant women who use drugs who receive prenatal care requires systems-level rather than only individual-level changes. These changes require a paradigm shift to viewing drug use in context of the person and society and acceptance of responsibility for unintended consequences of public health bureaucratic procedures and messages about effects of drug use during pregnancy.
\end{abstract}

S. C. M. Roberts ( $₫)$

Alcohol Research Group, 6475 Christie Ave, Suite 400,

Emeryville, CA 94608, USA

e-mail: sroberts@arg.org

S. C. M. Roberts - C. Pies

School of Public Health, University of California, Berkeley,

Berkeley, CA 94720, USA
Keywords Illicit drugs · Prenatal care . Pregnant women · Consumer involvement

\section{Introduction}

Pregnant women who use drugs are over-represented among women who receive late, limited, and no prenatal care [1-5]. Similar to pregnant women in general [6], women who use drugs and receive adequate prenatal care generally have better pregnancy outcomes than women who use drugs and do not receive adequate care [7-16]. It is unclear whether these improvements are due to prenatal care or if lack of prenatal care is a proxy for other risk factors associated with poor outcomes [13, 17]. Nevertheless, lack of prenatal care clearly limits opportunities for offering other health promoting interventions.

The limited research suggests that women who use drugs during pregnancy face the following barriers to prenatal care: difficulties with transportation and health insurance [18], "drug lifestyle" [19], fear of having drug use identified by providers [20], and fear of legal repercussions [21], including Child Protective Services (CPS) reports [22]. In addition, a recent study examined whether drug use itself or factors associated with drug use are barriers [23]. The study found that both drug use and factors associated with drug use are barriers, although this differs depending on the specific drug.

The existing research primarily tests researchers' a priori hypotheses [24]. Thus, it may exclude some key barriers. In addition, it has focused on determining the most common barriers [18] and on determining which risk factors explain the most variance in limited prenatal care [23]. While each are important, they do not provide information on how drug use or factors associated with drug use 
become barriers to prenatal care. With the goal of informing interventions to reduce barriers to prenatal care for women who use drugs during pregnancy, this qualitative study identifies women's perspectives on barriers to prenatal care and seeks to understand the processes through which drug use and factors associated with drug use during pregnancy become barriers.

\section{Methods}

This exploratory qualitative research was conducted between September and December 2006 in a northern California county. The county has a population of just over one million people, and is diverse in terms of race/ethnicity, income, and rural/urban status. Goals were to identify barriers to prenatal care and factors that encourage use of prenatal care by pregnant women who use alcohol and/or drugs and engage women in identifying strategies to reduce barriers. Human Subjects approval was obtained from University of California, Berkeley and informed consent was obtained from each participant.

Women with current alcohol and/or drug use or a history of substance abuse who were pregnant or had a child 2 years old or younger were eligible and were recruited from substance abuse treatment, a home-visiting program, and the Women, Infants, and Children (WIC) Program. Staff at these sites recruited women through a standardized script and posted flyers. Women then self-identified to the lead investigator (first author) either by phone or when she was onsite at the agency/organization. The intention of this purposive sampling strategy was to find pregnant women and new mothers who were currently using alcohol and/or drugs or had a history of alcohol and/or drug use during pregnancy who could talk about challenges that pregnant women who use alcohol and/or drugs face in entering and continuing prenatal care. Despite our intention of including women who used alcohol only, both alcohol and drugs, and drugs only, our sample only includes women using drugs, either alone or in combination with alcohol. It does not include women using alcohol without drugs.

Thirty-eight women participated. Twenty semi-structured interviews [25] and two focus groups (with eight and ten women each) were conducted. About one half of interview participants $(n=11)$ and all focus group participants were recruited from treatment. Interview and focus group guides addressed: women's thoughts about and experiences with prenatal care; barriers and facilitators to prenatal care for women who use alcohol and/or drugs; and women's thoughts about how the health department and health care providers could encourage women who use alcohol and drugs to enter prenatal care earlier, including ideas for a community awareness campaign. Women were also asked close-ended questions about demographics, timing of entry to prenatal care, and type of substance (alcohol and/or which drug) they used. Focus group participants provided this information in exit surveys. Due to an error with exit survey printing, women in focus groups were not asked questions about timing of prenatal care entry. The questions about alcohol and drug use were used to classify participants as using alcohol only, alcohol and drugs, or drugs only. Women were treated as study participants, key informants, and collaborators in community awareness campaign development. Women who were not pregnant at study participation $(74 \%)$ were asked about their most recent pregnancy.

Interviews and focus groups lasted approximately 60 and $90 \mathrm{~min}$, respectively and were recorded on audiocassette. Participants received \$30 and \$20 Target gift cards for interviews and focus groups.

Interviews and focus groups were transcribed verbatim and supplemented by notes. The transcriptions, combined with women's drawings of their ideas for the community awareness campaign, served as the basis for the analysis.

Coding was completed in a multiphase, iterative process. We had some general ideas of the barriers women might report prior to initiating the study. However, we did not have an a-priori coding scheme. Initial codes were developed in an inductive process [26] based on the first nine interview and both focus group transcripts. Codes were then added and refined based on the remaining eleven interviews. A codebook was created and then used to code the entire set of interview and focus group transcripts. Memos were used during coding to track ongoing analysis insights and after coding was completed to explore different aspects of identified themes and determine the number and quality of quotations supporting themes and different aspects of themes [27].

Case-studies, a cross-case study, and typology were also used [28]. Case studies of each interview participant were created to document the timing of prenatal care entry in relation to drug use cessation and factors that facilitated or hindered prenatal care entry. A cross-case study using data from all interview participants then categorized each woman based on her trimester of prenatal care entry and timing of drug use cessation. Health insurance status and previous CPS involvement emerged as themes and were added to the cross-case study. Timing of prenatal care entry, timing of drug use cessation, and structural barriers were then graphed to explore the relationships between timing of each behavior and structural barriers. Fisher's exact tests were used to test (1) whether problems with health insurance were associated with entry after first trimester and (2) whether entering after first trimester and/or having stopped use before entering were associated with previous CPS involvement. The statistical significance of 
the second test differed depending on whether the denominator was restricted to only those with at least one child prior to the index pregnancy; however, the trend was in the same direction for both. Findings from the full sample are reported. Finally, women were categorized based on how they responded to common fears, such as fears of being reported to CPS. For example, a typology [28] was created based on subthemes of similarities and differences [24] in ways that women respond to their fears of being reported to CPS in relation to prenatal care.

Validity checks included (1) respondent validation, where initial findings were shared with other women similar to initial participants, staff at agencies where participants were recruited, providers, and policymakers and feedback requested; (2) field time of more than 3 years that the lead investigator spent in the study setting; (3) use of multiple methods of data collection (interviews and focus groups) to triangulate findings relating to barriers to and facilitators of prenatal care; and (4) checks of how supported a key finding relating to fear of CPS was both across and within interviews [26, 27]. This final check was conducted after coding was completed to ensure that our finding was not driven by only one or two interviews.

\section{Results}

\section{Sample Description}

Participants were a racially and ethnically diverse sample of 38 low-income English-speaking pregnant and parenting women. About one-fourth (26\%) were pregnant at the time of study participation. Those who were not pregnant had a child 2 years old or younger. Most had received some prenatal care in their most recent pregnancy: $50 \%(n=10)$ of those participating in individual interviews entered in their first trimester; 25\% $(n=5)$ second trimester; and $20 \%(n=4)$ third trimester. Five percent $(n=1)$ received no prenatal care. Most women used more than one substance. Methamphetamine (61\% $n=23)$ and crack/ cocaine $(16 \% n=6)$ were the most common primary substances. Many used alcohol (42\% $n=16)$, but none reported an "alcohol only" pattern of use.

\section{“Same Reasons Somebody Who's Not Using Goes"}

Women reported attending and avoiding prenatal care for the "same reasons somebody who's not using goes," that is, reasons not connected to their drug use. A main reason they reported attending was "to make sure the baby's ok." Women reported going for checkups, information, answers to questions, reassurance, prenatal vitamins, and to avoid birth defects and other health problems.
[Prenatal care] affects a baby a lot. If, you're having any conditions or whatever, then [doctors] can, it minimizes the chances of your child being born with deficiencies.

With the doctor monitoring the baby and finding out if it's going to be a healthy baby, if everything's gonna be ok, if everything's growing right, [if] all the toes and fingers are there. That way they can detect infant problems early on and maybe help that situation.

Having health insurance, a belief in the utility of prenatal care, and social support also facilitated prenatal care use.

Women also reported not attending prenatal care for reasons unconnected to their drug use. These reasons included extrinsic barriers, such as problems with transportation, health insurance, and scheduling appointments, and feeling that providers do not listen, take concerns seriously, or spend enough time with them.

He wasn't answering my questions, he was very rushed. I'm trying to ask questions and he answered them on his way out the door. Then when I switched over to [new prenatal care site] I was voicin' concerns about my pregnancy and they were just pushed off, not taken care of, pushed off. I wasn't happy about that.

\section{Drug Use as Barrier}

Drug use itself was also a barrier. A few women reported prioritizing opportunities to use drugs and get high over prenatal care.

Dope prevented me from going [to the doctor]...My husband kept trying. He tried driving me, making appointments for me, everything. I was just too doped up to hear anything.

\section{Drug Use and Extrinsic Barriers}

\section{Multiple Simultaneous Risk Factors}

Women also faced extrinsic barriers: lack of transportation, health insurance, and financial barriers; homelessness; and bureaucratic barriers relating to obtaining insurance and scheduling appointments. Problems with health insurance were common and predicted later entry to prenatal care [See Fig. 1]. Some women attributed these barriers to their drug use. Many women described ways in which drug use interacted with and exacerbated these barriers. Bureaucratic barriers were especially significant for women who started to seek care later in pregnancy. 
Fig. 1 Trimester of prenatal care entry and insurance problems among interview participants $(n=20)$

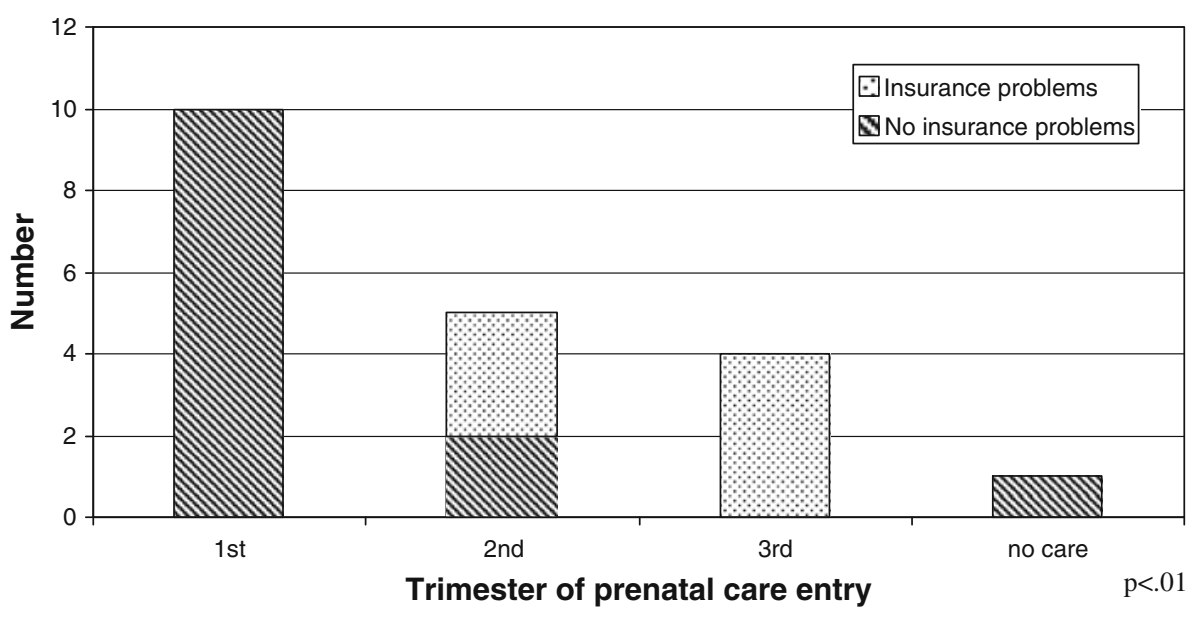

Women reported experiencing multiple extrinsic barriers simultaneosly. Multiple simultaneous barriers seemed to make resolving extrinsic barriers more difficult. For example, obtaining health insurance was especially difficult for one homeless woman. She reported:

I had always intended on going and having prenatal care, but the first blocker was the welfare department and getting Medi-Cal...They had denied me Medi-Cal because I was homeless [and therefore didn't have an address].

Some women saw drug use as related to and even as causing some extrinsic barriers. For example, one woman reported having been with a boyfriend in another town using drugs and not having her own transportation to get to prenatal appointments. Other women talked about how drug use left them with few resources, which then made it difficult to resolve the barriers. As one explained:

[My drug use made it hard for me to get an] appointment because by the time I found out I was pregnant, I had zero dollars, zero friends, a car that I couldn't drive, I didn't have internet, I didn't have telephone, and finding services to get the ball rolling in that way. Then in the phone book it doesn't exist. So if you don't have internet access, you're kind of in the dark.

Resolving bureaucratic barriers took persistence and determination. Drug use made resolving bureaucratic barriers more difficult because of both competing priorities and system gaps. Drug use itself, the stress of reducing or managing drug use, and the stress of leaving abusive partners with whom women used drugs were factors that women described as making it difficult to prioritize resolving bureaucratic barriers.
I didn't have Medi-Cal. I was very confused about how to go get emergency Medi-Cal, how it would only last for like 90 days and then how I'd have to go back and re-apply and then have to wait for that to come through, and how to find a doctor. It took me the longest time to try and see a doctor. My sister, she got pregnant and she sees own her private doctor, she also has Medi-Cal. It's just like, why is it so easy for her and like the world coming down on and I don't know what to do...People were telling me you need to see a doctor, but you need to wait for all these things to come through, and it was just stressful. Especially for someone who's coming off drugs and trying to do what they're supposed to. Even just getting through 1 day is stressful.

[I had gotten pregnant] through a sexual abuse with my ex [who introduced me to meth], so part of me shut down emotionally and didn't want to even accept that I [was] pregnant...[so], prenatal care wasn't high on my list, [figuring out how to get insurance] kind of just got pushed to the side because of my emotional issues, trying to deal with how I was going to leave him.

Some women also reported having unique concerns or situations related to their drug use that conflict with bureaucratic procedures. For example, a few women mentioned drug-related paranoia. One woman explained how this paranoia made it difficult to complete forms in public places.

You can't fill out Medi-Cal forms and everything if you're paranoid. You're afraid everybody's looking at you, or everybody sees that you're on drugs. 
Other women mentioned delays in discovering pregnancy. Some saw these delays as due, in part, to drug use. These delays led to them to begin obtaining insurance and scheduling appointments later in pregnancy. Starting these processes later created additional barriers, especially with scheduling appointments.

I didn't know where to go, my boyfriend just drove me to [county clinic] to make an appointment. We just waited in that line at the information window 12 over there, the information booth, went up to the window and said I'm pregnant. The woman said, how far along are you? I hadn't seen a doctor at that point so I had no clue. So, she said, let me see your stomach. And she said, oh you can't be more than 3 or 4 months pregnant. But it turned out that I was $6 \frac{1}{2}$ or 7 months pregnant at that time. Wow. So really I should have been seen at that time. 'Cause I went on her word, I waited to figure out where to go.

I started with the doctor she referred me to, took him a week to call me back, and then he told me he couldn't take me because I was past 7 months along, and he didn't take patients that far along.

\section{Drug Use and Social Support}

Drug use during pregnancy also interacted with women's ability to resolve extrinsic barriers by influencing access to social networks. Informational and tangible support from familial and drug-using networks helped women resolve extrinsic barriers. For example, informational support from these networks helped some women obtain insurance.

The lady across the street [from my parents], actually, our neighbor, who was the administrator at [local hospital], she, at one point, probably was the one that told my mom, look at Medi-Cal.

It was the first couple of days I was [at the treatment program] and there was a pregnant girl there that told me 'cause I had been tryin' to get the Medi-Cal straightened out.

Partners sometimes helped resolve extrinsic barriers.

My boyfriend kind of went the extra mile for me. He helped me get out of bed, made me go even when I didn't want to go stand on long lines just to get turned down, [helped] when we needed to sell our stuff so we could get gas money so we could go [to the] county [office].

In contrast, some women reported that their drug use isolated them from their families and other non-users. Some took steps to hide drug use and pregnancy from family and non-using partners, making it difficult to obtain support.
[My family] didn't even know I was pregnant. I did hide for about 7 months because I didn't show very well till about 7 months. I was trying to hide it anyways, 'cause that first step, admitting you're pregnant with the person they hated and despised and knew he was a druggie and causing problems with me.

Other women reported that when they reduced or stopped drug use, they lost access to drug-using friends and partners who wanted them to continue to use drugs with them. Conversely, a few also reported exclusion from drug-using networks due to pregnancy.

People don't give you drugs when you're pregnant.

Exclusion from these networks made it more difficult to obtain informational support to resolve extrinsic barriers.

Drug Use and Desire for Healthy Baby

Many women feared that their drug use had already harmed or would harm their baby. Some women felt guilty about their use because of this fear.

That guilt of knowing that you've used, 'cause you know 9 times out of 10 [it] will affect your baby in some way form or another.

Some addressed their guilt and concerns by attending prenatal care. Of women who attended, some reported doing so to compensate for the effects of drug use.

[I'm glad that I went to the doctor during my pregnancy] because I was able to see that my child was growing healthy and that I was doing all the right things as far as my diet and making sure that I ate lots of folic acid and stuff at the same time I was using.

A key component of compensating was obtaining prenatal vitamin prescriptions, which many women saw as having important health benefits. A few saw taking vitamins as helping compensate for drug use.

The baby has got to be healthy. I mean I need the prenatal pills. They['re] for the baby. I knew I wasn't eatin' right. I wanted to get as much nutrition, vitamins, minerals and everything that the baby needed as possible. So I made sure that I went to the doctor, and took my pills and ate as healthy as possible.

Some women also attended because they believed the doctor might discover and therefore minimize problems associated with drug use.

It's extremely important [to attend prenatal care] especially in the fact that you use drugs because if you let your provider know, they can make sure to check for...difficulties or problems that might arise 
from your use and you can minimize a lot of damage that way.

Other women attended to get reassurance that their baby was healthy. This reassurance helped relieve stress and anxiety.

I was so worried because I had used in the first couple of months that...there was going to be something wrong with my baby. Being able to go to prenatal care took a lot of that stress off me, 'cause they're telling me my baby's ok and I'm not this and I'm not that. That relieved a lot of stress on my part, a lot of stress.

Simply attending prenatal care also relieved guilt for some women by helping them feel they were doing something right. This feeling that they were doing something right, in turn, helped them feel good about themselves.

However, the guilt about effects of drug use sometimes kept women away from prenatal care. Some avoided prenatal care out of fear they would learn they had already harmed their baby.

The more clean I got, I was like out of there, I was like tripping, like hella trippin'...I d[id]n't know what's going on with my kid. The guilt was really bad. I was scared, I didn't want to know. I really didn't, I did not want to know if there was anything wrong.

Learning from the doctor they had harmed their baby by using drugs would have increased guilt. Others tried to deal with the guilt on their own. Some tried to reduce or stop their use. Others continued drug use to escape from guilt. Each led to delays in prenatal care entry.

The drugs lie to you in your brain, they tell you everything's gonna be ok, to don't worry about it, just smoke me, smoke me. But at the same time, you're knowing deep down in the back of the mind, especially when you're coming down off the shit, you know what I mean?... When you're coming down off of it, that's when you're feeling guilty about it, that's when you really start to feel guilty and that's when you regret. Until you get that next hit of course.

When women used drugs to calm their guilt, this use sometimes increased guilt. Women reported that both the drug use and the increased guilt from the drug use then made it more difficult to attend prenatal care.

\section{Drug Use and Fear of CPS}

Finally, most women feared that attending prenatal care while using drugs would lead to CPS reports and losing their children.
When you're using and you think about prenatal care, you're nervous and you're scared because you don't want anybody to take your baby. That's the first thing on your mind.

Most women avoided prenatal care or attempted to stop using drugs before attending prenatal care because of fear of CPS [See Fig. 2].

I didn't [go while] I was using because I was afraid that, if they had known, that CPS would have been involved, that Social Services would have taken my baby.

That whole time, that whole 9 months, you're like, I cannot go to this doctor because if I do, they're gonna take my kid or put [me] in jail for the rest of [my] 9 months just to take the baby when [I deliver].

A few attended in spite of fear of CPS because they prioritized their baby's health. One woman who used methamphetamine and marijuana throughout her pregnancy explained:

[Fear of CPS] made me not want to go, but because I was high risk, there was a greater chance of, I care more about my son being ok...so, I never missed $\mathrm{a}[\mathrm{n}]$ appointment.

Others attended because of fear of CPS. They saw prenatal care as increasing their chances of keeping the baby with which they were currently pregnant and reunifying with children who had been removed.

One of the reasons I went was because I didn't want them to take the baby away.

\section{Discussion}

Participants reported similar barriers to prenatal care as low-income women in general [29-31]. In addition, both drug use and factors associated with drug use influence prenatal care use. Drug use itself is a reason a few women do not attend prenatal care. However, for most women, drug use became a barrier to prenatal care by interacting with additional individual, interpersonal, systems, and policy-level factors. First, as has been found previously, pregnant women who use drugs face multiple barriers $[32,33]$. Experiencing multiple barriers simultaneously makes resolving each barrier more difficult. They also may be especially at risk for certain bureaucratic barriers, such as finding doctors willing to start seeing women during their third trimester. Second, women believe that drug use during pregnancy is very harmful to the fetus. While a 
Fig. 2 Timing of prenatal care entry and drug use cessation and previous CPS involvement among interview participants $(n=20)$

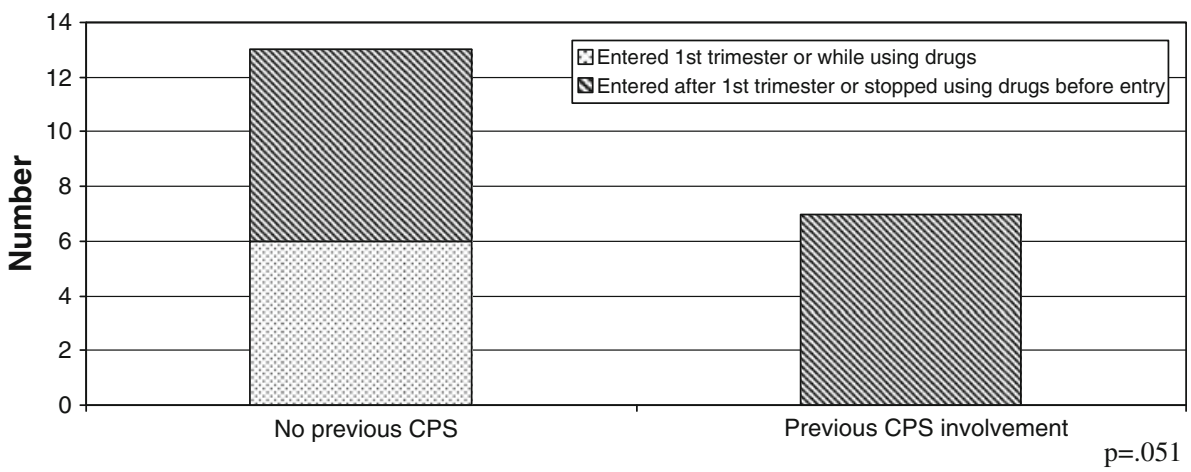

motivator to attend prenatal care for some women, this belief appears to scare other women to the point that they delay entering prenatal care. Women's beliefs are consistent with some public health messages about effects of drug use during pregnancy [34-36]. It is important to note that recent research suggests that drug use during pregnancy may not be as harmful as women believe and public health messages suggest [37, 38]. Third, women report isolation from potentially supportive networks due to their drug use during pregnancy. These same messages may stigmatize women who use drugs during pregnancy. This stigma appears to isolate women from social networks that could facilitate prenatal care use. Finally, as suggested by ACOG and found by other qualitative, but not quantitative research [18, 22, 23, 39], fear of CPS reports is a common and significant barrier. Fear of CPS reports may be warranted based on current policy and practice [40-42]. While drug use itself is a factor for some women, it does not appear that late or limited prenatal care among women who use drugs is caused solely by drug use itself. Rather, late or limited prenatal care may be better understood as one rational response to public health messages and CPS reporting practices, and as an indicator of systems-gaps.

These findings should be interpreted in light of the study's limitations. First, the sample is a small non-representative sample of agency-involved women in one county. Second, few participants were using drugs at the time of participation and many were or had been involved with CPS, each of which may have influenced what they chose to focus on during interviews and focus groups. Third, the assessment of alcohol and drug use only included questions about type of substance and did not include quantity/frequency questions or questions about problem severity, which limits generalizability. However, the questions asked suggest that findings apply to women who use methamphetamine or cocaine, either alone or in combination with marijuana, alcohol, and other drugs; and may not generalize to women using opiates or using marijuana only, because they were not represented in the sample. However, more research with better alcohol/drug measures is needed to confirm these findings and to determine whether women with more or less frequent use or more or less severe problems experience the same barriers. Fourth, other counties may respond differently to drug use during pregnancy and may have different systems, such as easier thirdtrimester entry to care or services to assist homeless women obtain insurance. Finally, the direction of causality between drug use and extrinsic barriers is not possible to determine. While some participants spoke of their drug use as causing the barriers, it is possible that any association between the two is not a simple uni-directional causal relationship [43] and that each indicate higher risks from more distal factors [44].

This study also has strengths. Findings are largely consistent with prior research on barriers to prenatal care for pregnant women who use drugs [18, 19, 22, 23]. However, this research also extends previous research by (1) identifying new barriers that have not been previously documented-fear of the effects of drug use and isolation from social networks; (2) finding additional support that fear of CPS is a barrier; (3) identifying how drug use becomes a barrier; and (4) regardless of the direction of causality, describing ways in which multiple simultaneous barriers make it more difficult to resolve barriers. This study also extends previous research by identifying systems-level barriers, including those related to public health bureaucratic procedures, messages, and CPS reporting policies/practices, rather than solely focusing on individual-level risk factors.

\section{Conclusions}

Findings suggest that reducing the number of pregnant women who use alcohol and drugs who receive late or limited prenatal care requires more than telling women to stop drug use. It requires acknowledging the complexity of women's decision-making about prenatal care, the diversity among women who use drugs during pregnancy, and a focus on changing systems and not solely getting women to 
change. Some interventions that may increase prenatal care utilization are: (1) new messages about the effects of drug use during pregnancy that identify steps that pregnant women who have already used drugs can take to increase chances of having healthy babies; (2) clarified CPS reporting policies; (3) streamlined insurance applications; and (4) easier access to providers who accept women in their third trimesters. Addressing these systems-level barriers as opposed to focusing on drug use as an isolated and silver-bullet risk factor will require a paradigm shift to viewing drug use and prenatal care utilization in the context of multiple interacting risk factors and social environment [33, 45, 46]. It will also require increased recognition that public health messages and bureaucratic procedures can create barriers and acceptance of responsibility for unintended [47] and potentially iatrogenic [48] consequences of these messages and procedures.

Acknowledgments This project was supported by a March of Dimes Community Award and NIAAA Graduate Training on Alcohol Problems, T32 AA07240. An earlier version of this paper was presented at the 70th Annual Conference on Problems of Drug Dependence (San Juan, Puerto Rico 2008).

Open Access This article is distributed under the terms of the Creative Commons Attribution Noncommercial License which permits any noncommercial use, distribution, and reproduction in any medium, provided the original author(s) and source are credited.

\section{References}

1. Melnikow, J., Alemagno, S. A., Rottman, C., \& Zyzanski, S. J. (1991). Characteristics of inner-city women giving birth with little or no prenatal care: A case-control study. Journal of Family Practice, 32(3), 283-288.

2. Kelly, R. H., Danielsen, B. H., Golding, J. M., Anders, T. F., Gilbert, W. M., \& Zatzick, D. F. (1999). Adequacy of prenatal care among women with psychiatric diagnoses giving birth in California in 1994 and 1995. Psychiatric Services, 50(12), 15841590.

3. Hankin, J., McCaul, M. E., \& Heussner, J. (2000). Pregnant, alcohol-abusing women. Alcoholism, Clinical and Experimental Research, 24(8), 1276-1286.

4. Pagnini, D. L., \& Reichman, N. E. (2000). Psychosocial factors and the timing of prenatal care among women in New Jersey's Health Start program. Family Planning Perspectives, 32(2), 56-64.

5. Maupin, R., Jr., Lyman, R., Fatsis, J., et al. (2004). Characteristics of women who deliver with no prenatal care. The Journal of Maternal-Fetal \& Neonatal Medicine, 16(1), 45-50.

6. Alexander, G. R., \& Kotelchuck, M. (2001). Assessing the role and effectiveness of prenatal care: History, challenges, and directions for future research. Public Health Reports, 116(4), 306-316.

7. Green, M., Silverman, I., Suffet, F., Taleporos, E., \& Turkel, W. V. (1979). Outcomes of pregnancy for addicts receiving comprehensive care. American Journal of Drug and Alcohol Abuse, 6(4), 413-429.
8. MacGregor, S. N., Keith, L. G., Bachicha, J. A., \& Chasnoff, I. J. (1989). Cocaine abuse during pregnancy: Correlation between prenatal care and perinatal outcome. Obstetrics and Gynecology, 74(6), 882-885.

9. Broekhuizen, F. F., Utrie, J., \& Van Mullem, C. (1992). Drug use or inadequate prenatal care? Adverse pregnancy outcome in an urban setting. American Journal of Obstetrics and Gynecology, 166(6 Pt 1), 1747-1754. (discussion 54-56).

10. Racine, A., Joyce, T., \& Anderson, R. (1993). The association between prenatal care and birth weight among women exposed to cocaine in New York City. Journal of the American Medical Association, 270(13), 1581-1586.

11. Chazotte, C., Youchah, J., \& Freda, M. C. (1995). Cocaine using during pregnancy and low birth weight: The impact of prenatal care and drug treatment. Seminars in Perinatology, 19(4), 293-300.

12. Berenson, A. B., Wilkinson, G. S., \& Lopez, L. A. (1996). Effects of prenatal care on neonates born to drug-using women. Substance Use and Misuse, 31(8), 1063-1076.

13. Faden, V. B., Hanna, E., \& Graubard, B. I. (1997). The effect of positive and negative health behavior during gestation on pregnancy outcome. Journal of Substance Abuse, 9, 63-76.

14. Burkett, G., Gomez-Marin, O., Yasin, S. Y., \& Martinez, M. (1998). Prenatal care in cocaine-exposed pregnancies. Obstetrics and Gynecology, 92(2), 193-200.

15. Richardson, G. A., Hamel, S. C., Goldschmidt, L., \& Day, N. L. (1999). Growth of infants prenatally exposed to cocaine/crack: Comparison of a prenatal care and a no prenatal care sample. Pediatrics, 104(2), e18.

16. El-Mohandes, A., Herman, A. A., Nabil El-Khorazaty, M., Katta, P. S., White, D., \& Grylack, L. (2003). Prenatal care reduces the impact of illicit drug use on perinatal outcomes. Journal of Perinatology, 23(5), 354-360.

17. Alexander, G. R., \& Korenbrot, C. C. (1995). The role of prenatal care in preventing low birth weight. Future Child, 5(1), 103-120.

18. Klein, D., \& Zahnd, E. (1997). Perspectives of pregnant substance-using women: Findings from the California Perinatal Needs Assessment. Journal of Psychoactive Drugs, 29(1), 55-66.

19. Milligan, R., Wingrove, B. K., Richards, L., et al. (2002). Perceptions about prenatal care: Views of urban vulnerable groups. BMC Public Health, 2, 25.

20. Roberts, S. C. M., \& Nuru-Jeter, A. (2010). Women's perspectives on screening for alcohol and drug use in prenatal care. Women's Health Issues (in press).

21. Poland, M. L., Dombrowski, M. P., Ager, J. W., \& Sokol, R. J. (1993). Punishing pregnant drug users: Enhancing the flight from care. Drug and Alcohol Dependence, 31(3), 199-203.

22. Murphy, S., \& Rosenbaum, M. (1999). Pregnant women on drugs: Combating stereotypes and stigma. New Brunswick, N.J.: Rutgers University Press.

23. Schempf, A. H., \& Strobino, D. M. (2009) Drug use and limited prenatal care: an examination of responsible barriers. American Journal of Obstetrics and Gynecology, 200(4), 412.e1-412.e10.

24. Ryan, G. W., \& Bernard, H. R. (2003). Techniques to identify themes. Field Methods, 15(1), 85-109.

25. Bernard, R. (1995). Research Methods in Anthropology. Walnut Creek: AltaMira Press.

26. Miles, M. B., \& Huberman, A. M. (1994). Qualitative Data Analysis: An Expanded Sourcebook. Thousand Oaks: Sage Publications.

27. Maxwell, J. A. (2005). Qualitative Research Design: An Interactive Approach. Thousand Oaks: Sage Publications.

28. Patton, M. Q. (2002). Qualitative Research and Evaluation Methods. Thousand Oaks: Sage Publications.

29. Kalmuss, D., \& Fennelly, K. (1990). Barriers to prenatal care among low-income women in New York City. Family Planning Perspectives, 22(5), 215-218. (31). 
30. Sunil, T. S., Spears, W. D., Hook, L., Castillo, J., Torres, C. (2010). Initiation of and barriers to prenatal care use among lowincome women in San Antonio, Texas. Maternal and Child Health Journal, 14(1), 133-140.

31. Phillippi, J. C. (2009). Women's perceptions of access to prenatal care in the United States: A literature review. Journal of Midwifery \& Women's Health, 54(3), 219-225.

32. Bendersky, M., Alessandri, S., Gilbert, P., \& Lewis, M. (1996). Characteristics of pregnant substance abusers in two cities in the northeast. American Journal of Drug and Alcohol Abuse, 22(3), 349-362.

33. Schempf, A. H., \& Strobino, D. M. (2008) Illicit drug use and adverse birth outcomes: is it drugs or context? Journal of Urban Health, 85(6), 858-873.

34. Baby Brochure (2003). (Accessed at http://www.daodas.state. sc.us/documents/babybrochure.pdf).

35. Ten Important Tips for Prenatal Care (2009). (Accessed June 19, 2009, at http://www.planned.org/site/PageServer?pagename=HS_ TenImportantTipsforPrenatalCare).

36. Illicit Drug Use During Pregnancy: Quick Reference Fact Sheets (2009). (Accessed June 16, 2009, at http://www.marchofdimes. com/professionals/14332_1169.asp).

37. Frank, D. A., Augustyn, M., Knight, W. G., Pell, T., \& Zuckerman, B. (2001). Growth, development, and behavior in early childhood following prenatal cocaine exposure: A systematic review. Journal of the American Medical Association, 285(12), 1613-1625.

38. Schempf, A. H. (2007). Illicit drug use and neonatal outcomes: A critical review. Obstetrical and Gynecological Survey, 62(11), 749-757.
39. ACOG. (2008). ACOG Committee Opinion No. 422: at-risk drinking and illicit drug use: Ethical issues in obstetric and gynecologic practice. Obstetrics and Gynecology, 112(6), 14491460.

40. Abel, E. L., \& Kruger, M. (2002). Physician attitudes concerning legal coercion of pregnant alcohol and drug abusers. American Journal of Obstetrics and Gynecology, 186(4), 768-772.

41. DHHS (2006) Parental drug use as child abuse: Summary of state laws. Washington, DC.: US Department of health and human services. Administration for children and families. Administration on children, youth and families. Children's Bureau.

42. Keeping children and families safe act 2003 108-36. In; 2003.

43. Johnson, T. P., Freels, S. A., Parsons, J. A., \& Vangeest, J. B. (1997). Substance abuse and homelessness: Social selection or social adaptation? Addiction, 92(4), 437-445.

44. Link, B. G., Phelan, J (1995) Social conditions as fundamental causes of disease. Journal of Health and Social Behavior.Spec No:80-94.

45. Lu, M. C., \& Halfon, N. (2003). Racial and ethnic disparities in birth outcomes: A life-course perspective. Maternal and Child Health Journal, 7(1), 13-30.

46. Misra, D. P., Guyer, B., \& Allston, A. (2003). Integrated perinatal health framework. A multiple determinants model with a life span approach. American Journal of Preventive Medicine, 25(1), $65-75$.

47. Sterman, J. D. (2006). Learning from evidence in a complex world. American Journal of Public Health, 96(3), 505-514.

48. Illich, I. (2003). Medical nemesis. 1974. Journal of Epidemiology and Community Health, 57(12), 919-922. 